\title{
TENSÕES E DESAFIOS NA FORMAÇÃO DE PESQUISADORES EM CIÊNCIAS SOCIAIS E HUMANAS
}

\author{
TENSIONES Y DESAFÍOS EN LA FORMACIÓN DE INVESTIGADORES EN \\ CIENCIAS SOCIALES Y HUMANAS
}

\author{
TENSIONS AND CHALLENGES IN THE FORMATION OF RESEARCHERS IN \\ HUMAN AND SOCIAL SCIENCES
}

\author{
Lucas KROTSCH ${ }^{1}$ \\ Martín AIELLO ${ }^{2}$
}

RESUMO: Este trabalho procura problematizar as dimensões que estruturam os espaços para a formação de pesquisadores nas ciências humanas e sociais na Argentina, principalmente, nos espaços de pós-graduação. O problema central é o fenômeno "tudo menos tese", mas isso coloca em destaque outras considerações, como a formação prévia, as tensões para que a pósgraduação seja mais produtiva em termos de resultados, as propostas curriculares e as estratégias didáticas. Analisar essas dimensões, de como os atores envolvidos vão configurando um campo, é fundamental, tanto para chegar a compreender como se pode produzir teses viáveis e com qualidade suficiente, como para contribuir para formar pesquisadores independentes na área e orientar as políticas públicas necessárias para melhorar essa atividade.

PALAVRAS-CHAVE: Formação de pesquisadores. Educação. Tese. Pós-Graduação.

RESUMEN: El trabajo procura problematizar las dimensiones que estructuran los espacios para la formación de investigadores en las ciencias humanas y sociales em Argentina, basicamente espacios de posgrados. El problema central es el fenómeno "todo menos tesis" pero esto pone en relieve otras consideraciones, como la formación previa, las tensiones para que los progrados sean productivos en términos de resultados, las propuestas curriculares y las estratégias didácticas. Analizar dichas dimensiones en clave de cómo los actores involucrados van configurando un campo es fundamental tanto para la llegar comprender como se puede producir tesis viables pero de calidad suficiente, como contribuir a formar investigadores independientes en el área, como para orientar las políticas públicas necesarias para mejorar esta actividad.

PALABRAS CLAVE: Formación de investigadores. Educación. Tesis. Posgrado.

${ }^{1}$ Universidad Nacional de Lanús (UNLa), 29 de septiembre 3901, B1832 Remedios de Escalada, Buenos Aires Argentina. Docente Investigador del Departamento de Planificación y Políticas Públicas. Doctorado en Ciencia Política por la Universidad de Barcelona. Licenciado en Ciencia Política por la Universidad de Buenos Aires. ORCID: https://orcid.org/0000-0002-6851-9154 E-mail: lkrotsch@gmail.com

${ }^{2}$ Universidad Nacional de Tres de Febrero (UNTREF). Mosconi 2736, Sáenz Peña, Buenos Aires, Argentina. Profesor titular regular del Departamento de Ciencias Sociales. Doctorado en Educación por la Universidad de Barcelona. Licenciado en Sociología por la Universidad de Buenos Aires. ORCID: https://orcid.org/0000-00024930-1723 .E-mail: maiello@untref.edu.ar

RIAEE - Revista Ibero-Americana de Estudos em Educação, v, Araraquara, v. 14, n. esp. 3, p. 1847-1861, out., 2019. E-ISSN: $1982-5587$. 
ABSTRACT: This work aims to problematize the dimensions that structure the spaces for the formation of researchers in the human and social sciences in Argentina, basically postgraduate courses. The central problem is the phenmenon "everything but thesis" which highlights other considerations, such as prior training, tensions for postgraduate studies to be productive in terms of results, curricular proposals and teaching strategies. Analyzing these dimensions in terms of how the actors involved are configuring a field is fundamental both for understanding how to produce viable theses of sufficient quality, useful to train independent researchers in the area, as well as guiding the necessary public policies to improve this activity.

KEYWORDS: Research training. Education. Thesis. Postgraduate.

\section{Introdução}

A necessidade de desenvolvimento de uma área educativa põe em tensão os componentes desta problemática a partir da obrigação de chegar a um resultado desejável, partindo de um ponto desfavorável, o qual gera demanda por uma política educativa, seja em nível institucional ou de sistema. Este é o caso da pós-graduação acadêmica nas ciências humanas em geral e na área de educação, em particular na Argentina. A situação é sintetizada a partir da baixa tradição de formação em pesquisa em comparação com outras disciplinas, a necessidade dos acadêmicos em obter um mestrado e doutorado e as configurações institucionais e de sistema para garantir processos e resultados de qualidade. Isso mostra uma série de vínculos no processo de configuração entre diferentes atores: alunos de pós-graduação, professores, acadêmicos, avaliadores etc.

O que propomos neste trabalho é objetivar essas tensões com base nas experiências que os autores vêm adquirindo em diferentes áreas da formação de doutores orientadas para a produção de teses acadêmicas, basicamente na educação. É urgente se livrar de propostas reducionistas que tentam isolar variáveis para encontrar causas específicas para problemas, que para nós são sempre integrais.

\section{Condições iniciais de formação de doutores nas Ciências Humanas e na Educação na Argentina}

A lei n ${ }^{\circ} .24 .521$ da Educação Superior de 1995 introduziu normativamente a acreditação das pós-graduações na Argentina a partir do seu artigo 46. Essas experiências haviam sido antecipadas pela Comissão de Acreditação de Graduados (CAP), durante a primeira metade daquela década (MARQUIS, 2009). Os modelos de acreditação de pós-graduação em ambos os momentos levam em conta a experiência anterior realizada no México e no Brasil. Atualmente, 
a Resolução do Ministério da Educação que regulamenta nacionalmente a acreditação de pósgraduação é a n⿳o. 160, do ano de 2011.

A grande diferença em relação ao Brasil é que tanto os programas profissionais quanto os acadêmicos são credenciados. As carreiras de pós-graduação reconhecidas são especializações (de 360 horas mínimas de aula), mestrados (de 540 horas mínimas de aula), tanto profissionais como acadêmicas, e doutorados (estes últimos sem carga horária mínima). Por sua vez, os ciclos de pós-graduação não são articulados: não é necessária uma especialização para fazer um mestrado ou um mestrado para fazer um doutorado. Tampouco, os programas de mestrado e doutorado são credenciados como um todo, mas cada um independentemente, embora institucionalmente as especializações se articulam com mestrado e estes com doutorado.

Isto significa que em algumas áreas o doutorado é mais desenvolvido e em outras o mestrado e as especializações. Por exemplo, para o ano de 2013, nas áreas de Ciências Básicas havia 4.929 alunos em doutorado e apenas 1805 e 630 em mestrado e especialização, respectivamente. No entanto, nas Ciências Humanas havia 5.434 alunos em doutorado, 10.449 em mestrado e 15.783 em especializações (FERNÁNDEZ LAMARRA et al., 2018). Para o campo das Ciências Humanas, os doutorados passaram de 65 em 2003 para 98 em 2014, tendo um aumento de $27 \%$ nas inscrições e $20 \%$ da demanda total do sistema (JEPPESEN et al., 2016). Na Educação, a diferença é ainda maior, sendo 1.359 alunos de doutorado, 4.465 de mestrado e 11.620 de especialização para 2013 (FERNÁNDEZ LAMARRA et al., 2018).

Para guiar o argumento, partimos de um fato específico: na Argentina, a oferta de programas de doutorado está crescendo constantemente. A demanda também cresce, mas a taxa de graduação permanece quase constante. Ao mesmo tempo, a taxa de graduação é sustentada por bolsas de estudo concedidas pelo Conselho Nacional de Pesquisas Científicas e Técnicas (CONICET), que destina bolsas para carreiras científicas: os bolsistas do CONICET eram $31 \%$ dos alunos de 2012, e 66\% dos graduados (JEPPENSEN et al., 2016). Claramente, as Ciências Humanas em geral e a educação em particular não têm um peso relativo na concessão de bolsas. Além disso, seu perfil de estudantes de pós-graduação profissional também não promove uma melhora. Não há dados oficiais, mas estima-se que a taxa de formação de doutores em educação seja entre 12 e $15 \%$.

Por outro lado, não contamos nas ciências humanas com a tradição de formar pesquisadores incorporando-os em equipes de pesquisa consolidadas. A grande maioria daqueles que se candidatam a um doutorado têm experiência em pesquisa graças à conclusão de uma especialização e/ou mestrado e não porque participam ativamente de um ou de vários 
projetos de pesquisa. Esses dados concretos sugerem uma série de problemas que abordaremos a partir das tensões que nos propusemos objetivar neste trabalho.

\section{Os eixos da problematização para uma formação com qualidade nos cursos de pós- graduação acadêmica em Ciências Humanas e Educação}

É importante enquadrar a formação de doutores em educação no lócus de pesquisa e na lógica de produção e reprodução de conhecimento no sistema educacional. Sem dúvida, os problemas que encontramos no doutorado em relação à formação em pesquisa e à concepção da produção de conhecimento não são específicos deste nível. Somos formados em um esquema no qual as funções de transmissão e produção são claramente definidas, assim como quem é responsável por elas. Isso é visto, ainda que em menor grau, em estudos de graduação em que um número muito pequeno de alunos está disposto ou apto a participar da função de pesquisa. A abordagem massiva se dá por meio de materiais metodológicos demasiadamente teóricos e abstratos, devido a sua distância da prática efetiva e recorrente.

A discussão se um professor deve investigar ou um pesquisador deve praticar o ensino é um sinal claro dessa divisão já consolidada. Pode até ser visto nos resultados da pesquisa que ocorre nas unidades acadêmicas em que o modelo de contratação é realizado sob a figura do professor-pesquisador.

\section{O estudante de doutorado em Ciências Humanas e na Educação}

Este trabalho não enfoca o que deveria ser a formação de pesquisadores em termos ideais, mas se propõe a refletir sobre problemas observados em programas cujo objetivo é fornecer esse tipo de formação. A defesa de uma tese, que anos atrás era o ponto de chegada de uma extensa carreira acadêmica, hoje é, na maioria dos casos, um ponto de partida após a conclusão do curso. Os estudantes são cada vez mais jovens, não apenas com menos experiência em pesquisa e, acima de tudo, vivencial e profissional.

Os títulos valem menos e, portanto, as instituições devem gerar títulos mais altos para os mesmos resultados históricos. Cada vez mais um doutorado não é uma opção, mas uma necessidade para acessar posições que antes exigiam certificações menores. Por outro lado, a figura crescente do professor-pesquisador como figura de recrutamento necessariamente vincula essas duas funções: o professor não deve apenas ensinar e o pesquisador não deve apenas investigar. Isso faz proliferar pesquisas que primam pela necessidade de cobrir horas de 
pesquisa, e ensino que prima por cobrir horas de ensino, como uma questão prioritária à vontade de investigar e à vontade de ensinar. Ou seja, mais e mais acadêmicos precisam de um doutorado em vez de desejar. O doutorado os torna mais competitivos, para além de pesquisarem efetivamente ou não.

Supõe-se que o grau de autonomia de um estudante de doutorado é muito maior do que o de um estudante de pós-graduação em termos da ajuda necessária para realizar com sucesso o processo de certificação do nível. Os problemas que temos hoje em relação à terminalidade do doutorado e à nova carreira acadêmica nos obrigam a rever esse pressuposto.

\section{O início do processo de formação e a estruturação de vínculos}

O ingresso do estudante em um doutorado implica em assumir um compromisso. Ambas as partes se comprometem a dar o melhor de si para o objetivo final, a tese de doutorado. Mas, o que significa isto? As partes devem ter o mais claro possível o que se espera dessa relação. O ingresso seria dado, então, por um conhecimento compartilhado das perspectivas dos atores envolvidos em relação à realização do objetivo final, a graduação do aluno e a certificação pela instituição de um programa de pós-graduação. Desde que a instituição esteja comprometida com o participante no que diz respeito a fornecer o apoio necessário para atingir este objetivo, da mesma forma o aluno também assume um compromisso com a dedicação e esforço que deve ser feito.

A fim de nos unirmos fortemente a esse espírito, é necessário ter presentes as ferramentas disponíveis para os diferentes perfis que os alunos podem ter, a fim de que sejam adequadamente atendidos em suas necessidades razoáveis para o nível. Por necessidades razoáveis para o nível entendemos aqueles que justificam a entrada do aluno no programa pela instituição. A título de exemplo drasticamente claro: um programa precisa atingir um número mínimo de inscritos para funcionar, gerando relaxamento no perfil que a instituição considera adequado para admissão; isso deve ser acompanhado da convicção efetiva daqueles que gerenciam este programa que isso poderá afetar o compromisso necessário para que aqueles que possuem mais dificuldades tenham o apoio institucional necessário para atender às suas expectativas.

Caso não seja a instituição que avalia o conhecimento necessário para ingressar em um programa de pós-graduação, é aceitável que a certificação dos níveis anteriores responda por esse conhecimento. Aqui há dois caminhos a seguir caso o conhecimento para o 
desenvolvimento do programa não seja suficiente: um é desprender-se dos problemas do sistema como um todo, como se o programa de doutorado não fizesse parte dele e, finalmente, a falha fosse dos níveis anteriores; o outro é supor que o sistema é "um sistema" e que existem ou deveriam existir mecanismos para corrigir problemas de suas partes. Nós concordamos com esta última posição. Entre outras coisas, porque acreditamos que a qualidade dos pesquisadores e o conhecimento que eles podem produzir não podem ser efetivados sem uma concepção inclusiva sobre os processos que levam a essa formação. Talvez não possamos aceitar o desafio de incorporar qualquer pessoa que queira se incorporar a um credenciamento formal exigido pelo nível, mas sem considerar razoável que, quando um candidato é aceito, o compromisso assumido esteja na direção indicada.

Por outro lado, a instituição que aceitou um candidato, ou seja, que o tornou aluno do programa, já tem uma obrigação com relação a sua carreira no referido programa. Desse modo, o programa não pode nem deve ignorar as necessidades do aluno.

A declaração de intenções termina com o início de um programa de doutorado. É quando as expectativas dos diferentes atores começam a se alimentar, produzindo em cada um com efeitos diferentes. $\mathrm{O}$ esperado só pode ser medido uma vez que iniciada a ação se você tiver ferramentas que facilitem a reflexão. Professores, equipes de gestão, estudantes e contextos acadêmicos e sociais configuram redes complexas de interação objetivadora. Acreditamos que é importante não simplificar fenômenos altamente complexos. É por isso que vamos evitar falar sobre abandono, fracasso ou sucesso dos alunos, qualidade deste ou daquele programa ou desânimo ou entusiasmo deste ou daquele professor.

\section{O problema das "metodologias"}

Tende-se a apontar como os seminários mais complexos estão focados basicamente na dimensão metodológica das teses de doutorado. E é lógico que isso é assim por vários motivos, que dependem um do outro:

- A experiência limitada em pesquisa com a qual os candidatos, aspirantes a doutores, geralmente contam.

- O lugar que ocupam as metodologias. Se ensina "como" sem haver refinado o problema de pesquisa, "o que pesquisar". Ou seja, se pensa geralmente a metodologia como receita para fazer um produto que se desconhece. Isso torna o processo de autoavaliação 
contínua do doutorando muito difícil durante o processo de tese, em que o objeto de estudo está sendo refinado.

- A baixa integração entre os seminários que compõem o programa. Ou seja, em geral se considera os seminários como horas a cumprir para dar por cumprida a etapa de docência, mais que como insumos úteis para o objetivo final, em que a metodologia é um elemento central. É importante entender que a centralidade não deve isolar o conteúdo dos sujeitos metodológicos do "que se quer pesquisar".

\section{A inserção institucional do doutorando}

Uma questão interessante a ponderar é a tensão que existe entre o objetivo subentendido de uma tese de doutorado, que deve contribuir com novos conhecimentos sobre um problema relevante para determinado campo científico e fornecer o conhecimento para poder credenciar o título de doutor. Esta questão se articula à baixa incidência que encontramos no campo das ciências sociais e humanas da inserção anterior de doutorandos em equipes de pesquisa. Esse investimento em outros campos estabelece linhas de continuidade entre os projetos de pesquisa apresentados, individualmente, em programas de doutorado e equipes que trabalham em problemas complementares ao referido projeto. A formação do doutorando, neste caso, estaria articulada a pesquisas com colegas ou pesquisadores com mais experiência. A partir desta relação, há uma contribuição parcialmente individual para este trabalho conjunto e uma acreditação individual que, em termos concretos, valida algo mais do que uma capacidade individual. Em outras palavras, nesses casos, o programa de doutorado teve como objetivo geral identificar e credenciar aqueles que, fazendo sua parte específica, demonstram sua formação em pesquisa.

Aqueles que não têm ou estão sendo formados em equipes de pesquisa consolidadas e têm pouca experiência em pesquisa encontram no programa de doutorado sua primeira grande experiência em pesquisa. E esse primeiro grande compromisso com a pesquisa ocorre em um espaço acadêmico que tem como característica o trabalho autônomo e solitário. Aqui nos vemos com uma questão central: escasso acompanhamento em uma tarefa na qual há pouca segurança e experiência. Acrescenta-se a isso que é dado como certo que nesses níveis quem está cursando um doutorado deve saber como se manter por conta própria. Pedir ajuda neste nível não é bem visto, mas o fato é que é necessário. 


\section{A escrita acadêmica}

O problema não é apenas escrever, mas escrever o que você pode decidir escrever. Escrita acadêmica é, geralmente, considerada como algo monolítico e homogêneo, mas a verdade é que não é. Em um campo bastante promíscuo em relação à diversidade de perfis que recebem como aspirantes, o problema da escrita acadêmica se torna ainda mais complexo. Os campos disciplinares não só têm conceitos fortes que são facilmente identificáveis como parte da identidade do referido campo. Estes também têm estilos particulares de escrita, que um estudante de doutorado que vem de outros campos deve assimilar minimamente para objetivar sua argumentação em código e afinado com o dito campo.

O problema da pesquisa e o objeto de estudo de uma tese de doutorado nunca são relevantes, senão dentro de certos parâmetros conceituais e estilísticos que só podem ser reconhecidos dentro de um campo problemático específico. Quanto mais longe o aluno de doutorado estiver do gerenciamento relevante do que é discutido e como é discutido nesse campo problemático, mais complexo será o desenvolvimento de sua tese. Basicamente, o estudante de doutorado deve se reconhecer nesse campo problemático antes de ser reconhecido nele, o que, na maioria dos casos, ocorre cada vez mais quando a tese é defendida e publicada na forma de artigos independentes ou como uma única peça.

Internalizar o estilo apropriado de um campo ou disciplina requer tempo, espaços e ferramentas relevantes. Observamos que é comum iniciar um doutorado e nunca ter tido em mãos uma tese de doutorado. Isso quer dizer que o conhecimento sobre a coisa mais importante que está sendo feita para um doutorado, que é uma tese de doutorado, é muito pouco ou inexistente. E, à medida que o programa progride, não tende a reverter essa característica. Sem medo de errar, podemos dizer que não é costume trabalhar com teses de doutorado como insumos fundamentais em seminários e workshops, e apenas os estudantes de doutorado com maior formação ou inserção de pesquisa anterior consideram esses trabalhos como insumos relevantes. O paradoxo aqui é evidente.

\section{Tensões entre descrição, exploração e explicação}

Aceitando que, em nossas disciplinas, o método experimental implica um grau inacessível de complexidade para um projeto de pesquisa de doutorado, a maior tensão é entre o descritivo, o exploratório e o explicativo. Embora nos programas mencionados encontremos uma forte proeminência de projetos exploratórios, a verdade é que os resultados desses projetos 
acabam distribuindo esse corte em relação ao peso da descrição e da impossibilidade de adentrar na análise do problema de pesquisa. Os estudos exploratórios acabam dando mais peso à descrição do problema ou à sua identificação do que a análises que permitem ampliar a visão sobre os casos, proporcionando ao campo problemático novas dimensões e perspectivas para a abordagem de determinados problemas.

A proposta de seminários de formação doutoral não consegue corrigir essas questões; acreditamos que, em grande medida (entre muitas outras questões):

- A proposta temática dos seminários se baseia na diversidade de interesses e perfis de estudantes. Os próprios alunos indicam que precisam concluir as demandas dos seminários para começar a se preocupar com a tese de doutorado. É mais difícil descobrir quem indica que os seminários contribuíram para consolidar seu projeto de pesquisa.

- Os seminários preenchem vagas de conhecimento próprio dos níveis anteriores de treinamento e não o que se esperaria de um nível de doutorado.

- A proposta de seminários a ser oferecida mantém uma tensão entre os doutores que querem oferecer seu seminário em um programa de doutorado e têm a capacidade para tal e os horários apertados daqueles que podem oferecer seminários ajustados às exigências dos estudantes de doutorado.

- As oficinas de tese tendem a ser pensadas, a nosso modo de ver, como o currículo diretamente relacionado aos projetos de pesquisa que os seminários não conseguem proporcionar. Uma maior articulação entre os seminários e o objeto concreto do trabalho final seria desejável. Sabemos que por causa da heterogeneidade dos alunos isso é muito complicado, mas ainda é uma observação válida que nos faz continuar a pensar em como aplicá-lo.

O problema da descrição não é um problema de método, muito menos uma abordagem epistemológica ou ontológica. É um problema conceitual. As teses não chegam a ter a capacidade conceitual necessária para gerar o que Guba (1989) aponta como valor da verdade externa. Em geral, a análise das teses não pode transcender o campo e, portanto, a mera descrição de um primeiro nível indutivo. A falta de conexão com o campo conceitual impede que as análises sejam coerentemente ligadas aos conceitos e, portanto, transferidas para outros contextos. Isso está ligado à próxima dimensão. 


\section{Escassa presença de voz própria}

Um dos problemas que, provavelmente, está fortemente relacionado aos outros já mencionados é a capacidade limitada de contribuir com conhecimento do estudante de doutorado para o campo problemático em que ele procura inserir sua pesquisa. Encontramos estados de arte ou antecedentes como grandes compêndios de autores que dizem o que gostaríamos de dizer sobre um determinado tópico ou problema. Importantes monografias temáticas em que falta a voz do autor, ou seja, do doutorando. Parece, e isso nós capturamos sistematicamente nas entrevistas tutoriais que realizamos com sujeitos de vários programas que foram citados acima, que o doutorado se sente capaz de dizer apenas o que os outros dizem, mostrando uma baixa autoestima significativa à própria capacidade de traduzir análises de posição próprias com base nos autores analisados (sic). Temos trabalhado nessa questão há algum tempo, tentando empoderar o estudante de doutorado, aproximando-o de empregos semelhantes àqueles que ele pretende desenvolver, isto é, às teses já concluídas.

\section{Sobre os orientadores de tese}

A tarefa de orientar não é simples, e o valor que esse trabalho tem depende da experiência que a pessoa qualificada para essa tarefa credenciou como treinamento de recursos humanos. Geralmente, as principais referências acadêmicas em vários programas costumam estar repletas de obrigações acadêmicas nem sempre bem remuneradas. É evidente que estes perfis tentarão encontrar ou aceitar os melhores alunos de doutoramento ou, pelo menos, aqueles que garantam que o seu trabalho não será árduo e em vão. Nossa experiência indica que esse perfil é o mais solicitado, mas não, necessariamente, o que facilita um melhor desenvolvimento da pesquisa para o trabalho final de doutorado. Geralmente, esses perfis têm compromissos demais para concentrar esforços em um estudante de doutorado que precisa de muita proximidade e apoio para poder avançar.

A formação de recursos humanos é um dos muitos itens que compõem o currículo de um acadêmico, portanto, o interesse em fortalecer esse item dependerá de sua avaliação do valor que ele tem no conjunto de obrigações analisáveis.

Observamos que temos jovens doutores com grande necessidade de orientar teses de doutorado e que têm dificuldade de obter visibilidade para serem levados em conta. Isso se soma ao fato de que o "nome" na academia conta muito. No imaginário dos doutorandos, ter um "nome" de peso na direção de seu trabalho dará retorno ao produto final. É importante 
relativizar sempre esses preconceitos. A dedicação deste tipo de diretores, com "nome", aos tutoriais é geralmente menor que a dedicação daqueles que precisam começar a circular para aumentar o currículo e agregar experiência.

\section{Tese: avaliadores/tesistas e a defesa}

Não é fácil obter avaliadores para os trabalhos finais. Ainda é mais complicado obter avaliadores adequados para os diferentes tipos de teses apresentadas. Embora haja consenso de que uma tese deve ser avaliada por qualquer doutor, estamos convencidos de que essa não é a melhor maneira. A boa gestão forma um bom júri de acordo com interlocutores válidos e de acordo com o campo problemático do trabalho de pesquisa. A verdade é que, como observado acima, não é fácil obter avaliadores, pois é um trabalho que, no caso de ser remunerado, não está relacionado à demanda por ele.

Introduzimos este item neste artigo pois consideramos que a avaliação é parte do trabalho final do doutorando. Uma boa contribuição dos avaliadores para o trabalho árduo que a tese desenvolve até aquele momento deve ajudar na qualidade desse produto final chamado tese, se o objetivo ou um dos objetivos desse trabalho é gerar conhecimento inovador e pertinente em um determinado campo problemático.

Foi apontado como um problema não trabalhar desde o início do desenvolvimento da tese com teses acabadas para incorporar a lógica de "qual deve ser o trabalho final que devo fazer". Da mesma forma, podemos apontar o pequeno hábito de assistir a defesas de obras do mesmo nível. Conhecer o espaço de defesa oral de uma tese de doutorado envolveria atingir aquele espaço moderadamente utilizado para o mesmo que é colocado em jogo.

\section{Experiências de gestão bem-sucedidas ante algumas das tensões indicadas}

Os autores deste artigo, juntamente com outros colegas, têm trabalhado em vários dispositivos. Vamos compartilhar nossa experiência com um deles aqui. Em 2007, foi aprovada a criação do Programa Interuniversitário de Doutorado em Educação (PIDE). É, na sua origem, um Programa de Doutorado compartilhado por duas universidades nacionais, a Universidade Nacional de Lanús (UNLA) e a Universidade Nacional de Três de Febrero (UNTREF). Em 2012, a Universidade Nacional de San Martín (UNSAM) foi adicionada e credenciada pela Comissão Nacional de Avaliação e Credenciamento Universitário pela resolução nº 329/13. 
Tem modalidade presencial e a admissão é feita a cada dois anos, ou seja, é uma corte fechada a cada dois anos (a primeira corte começou em 2008). As entrevistas são realizadas antes das partes interessadas em que seu perfil é avaliado. É organizado curricularmente com seminários teóricos obrigatórios, sendo dois especificamente metodológicos e dois opcionais. Durante os dois anos em que os cursos destes seminários duram são realizados os atenuantes, em que os alunos têm a possibilidade de trabalhar juntos, mas colocando o acento em seu próprio projeto de pesquisa.

Este programa não deixa de ter os problemas próprios do nível. De fato, a maioria dos problemas observados neste trabalho resultam da própria experiência neste programa (sem ignorar, naturalmente, a situação do nível a nível nacional, regional e global). É por este motivo que em 2012 foi lançado o Âmbito de Desenvolvimento da Tese (ADT). É um espaço permanentemente aberto a estudantes de qualquer corte e em qualquer fase do desenvolvimento de seu trabalho de pesquisa. A particularidade desse espaço é que ele está aberto a problemas, no sentido amplo do termo. É um lugar de escuta e troca onde o objetivo principal responde à questão: como podemos desbloquear uma situação problemática?

Assume-se que o grau de autonomia de um estudante de doutorado é alto em relação ao seu grau em outros níveis do sistema. O real é que a suposição só pode ser considerada como tal, uma suposição. Respondendo ao compromisso mútuo implícito com a entrada do aluno no programa e a importante heterogeneidade de perfis em relação à sua formação anterior, o programa oferece um espaço de escuta permanente e responde de acordo. Consideramos que qualquer boa intenção tem limites, mas o ADT é valorizado de forma muito positiva pela administração e pelos estudantes.

Nesse espaço, abrimos uma dimensão afetiva como elemento importante a considerar como parte das condições de produção de uma tese de doutorado. Os sujeitos não podem ser abandonados a uma autonomia suposta ou desejável em um determinado nível de ensino. A verdade é que qualquer aluno em qualquer nível também está fora dos espaços específicos de treinamento, pois dentro desses espaços o aluno também é o sujeito que percorre outros campos. O ADT recebe aquele ser completo e o reconhece ao seu nível e com sua subjetividade. Assim, reconhecemos como ações concretas desse espaço:

- Escutar;

- Dar valor aos temores a fim de trabalhar com eles;

- Valorizar a experiência evidenciando seu valor ou desvalor acadêmico e propondo que melhor que uma folha em branco é a memória do processo que se vive para chegar a uma tese; 
- Diante de um comentário como "Eu tive esse problema e cheguei aqui sem poder problematizar isso, mas agora percebo que não era por ali", resposta: "Coloque em palavras $<<$ agora eu percebo >> voltando para o que você deixou para trás e coloque por escrito. Informe o processo que levou você de um ponto a outro". "Às vezes, esse tipo de problema pode ser visto como absurdo ou não de acordo com esse nível muito sagrado". O certo é que se esta observação surgir ou a manifestação de certa "vergonha", trabalhamos com ela;

- Aconselhar, em caso de ausência do orientador, na definição de perfis mais desejáveis com base no perfil do aluno de doutorado, o tipo de trabalho que ele quer fazer e o campo problemático em que ele vai procurar se inserir;

- Quando o trabalho está progredindo, fazemos papel de "advogados do diabo", tentando nos colocar no lugar do avaliado;

- Fornecer assistência teórica e metodológica a tempo;

- Acompanhar.

\section{A culpa não é (apenas) do estudante de doutorado: a título de conclusão}

É comum ouvir que o doutorando é aquele que não sabe, aquele que não pode, aquele que leva séculos para terminar a tese ou finalmente a abandona. Mas, na realidade, foi o programa que o aceitou como aluno e que, em muitos casos, graças à sua inscrição, conseguiu atingir um número suficiente de inscritos para que a instituição considerasse que um novo corte poderia ser aberto. O programa assume um compromisso, pelo que passa a ser um participante necessário dos resultados ou trajetória do aluno. Quando um sujeito se torna um estudante, então um compromisso foi feito. Um compromisso que distribui e compartilha responsabilidades. Wainerman (2018) sintetiza bem uma série de problemas do lado do estudante de doutorado da seguinte forma:

En un medio (en particular en ciencias sociales) en el que $<<$ se hace como que > se sabe lo que es una tesis, cómo se manejan banco de datos bibliográficos para elaborar estados del arte que permitan saber cuál es el conocimiento acumulado en el que se propone investigar, en el que no se sabe qué es y cómo se elabora un proyecto de investigación, en el que se confunden objetivos de investigación con objetivos de políticas o de resolución de problemas locales, puntuales, en el que no se sabe articular marco teórico con los objetivos y con el diseño de investigación, en el que se confunden descripción y explicación, en el que no se sabe qué es el genero textual tesis y cómo se produce, en el que es escasa la socialización académica, es decir, el conocimiento de las reglas, normas y valores de la academia (respetar la autoría de las fuentes, conocer los roles que se juegan en jornadas y 
conferencias, el manejo del tiempo de exposición, agradecimiento a los tutores, a las instituciones secantes y subsidiares, etc.), se desconoce que existen y cuáles son las instituciones nacionales y extranjeras a las cuales solicitar subsidios, y cómo relacionarse con colegas de dentro y fuera del país para formar redes de trabajo, es difícil alcanzar los estándares de doctorados de buen nivel que sean eficientes en la producción de investigadores (WAINERMAN, 2018, p. 257).

O que falta aqui, de acordo com nossos critérios, é a contrapartida institucional. Nós defendemos uma abordagem relacional para o problema. Ou seja, nada disso seria possível sem programas nos quais esses problemas fossem visíveis. A instituição faz parte do contexto em que os problemas são objetivados, isto é, onde os problemas emergem.

Acreditamos que não há outra maneira de considerar de forma complexa as condições de produção nas quais a formação de pesquisadores é credenciada. É provável que as condições atuais do nível convidem você a pensar em atualizações importantes. É uma realidade, por exemplo, a demanda cada vez mais notável de profissionalização dos doutorados. Sem dúvida, essa tendência responde a uma boa parte dos perfis que atualmente estão estudando neste nível.

\section{REFERÊNCIAS}

FERNÁNDEZ LAMARRA, N., PÉREZ CENTENO, C., AIELLO, M.; MARQUINA, M. La Educación Superior Universitaria Argentina: situación actual en el contexto regional. Sáenz Peña, Universidad Nacional de Tres de Febrero, 2018.

GUBA, E. G. Criterios de credibilidad en la investigación naturalista. En: SACRISTÁN, J. Gimeno; GOMEZ, A. P. (Orgs.). La enseñanza: su teoría y su práctica. Madrid: Akal, 1989.

JEPPENSEN, C. et al. La formación de doctores en Argentina: avances y desafios desde la perspectiva CONICET. Revista Argentina de Educación Superior, Año 8, Número 12 / 149-173, junio 2016.

MARQUIS, C. Posgrados y Políticas Universitarias. Consideraciones sobre el caso Argentino. Revista Argentina de Educación Superior, Año 1, Número 1 / 36-56, noviembre 2009.

WAINERMAN, C. Los doctorados en Argentina: crecimiento y desempeño. En: Barsky, O [et al.]. La Ley de Educación superior: impactos, desafíos e incertidumbres. Ciudad de Buenos Aires, Teseo, 2018. 


\section{Como referenciar este artigo}

KROTSCH L.; AIELLO, M. Tensões e desafios na formação de pesquisadores em ciências sociais e humanas. Revista Ibero-Americana de Estudos em Educação, Araraquara, v. 14, n. esp. 3, p. 1847-1861, out., 2019. E-ISSN: 1982-5587. DOI: 10.21723/riaee.v14iesp.3.12767

Submetido em: 25/03/2019

Revisões requeridas: 22/04/2019

Aceito em: 17/05/2019

Publicado em: 30/08/2019 